\title{
The Right to Health Care for Transsexual People in Cuba
}

\author{
Alberto Roque MD, R. Mayra Rodríguez MS
}

\begin{abstract}
Gender identity is a sociocultural construct based (in nearly every society) on a binary norm: female and male. Transsexual individuals suffer from intense family and social discrimination because they express a dissident sexuality incongruent with this norm. They assert they feel trapped in a body that does not belong to them, so they seek help from health professionals to modify their bodies, to "adapt their bodies to their minds." This essay discusses health care for transsexual persons in Cuba from a human rights perspective that does not pathologize their gender identification.
\end{abstract}

KEYWORDS Transsexualism, gender identity, sexual health, sexual reassignment surgery, gender role, human rights, prejudice, sexism, Cuba

\section{TRANSSEXUALITY AS A BIOMEDICAL CONSTRUCT}

Transsexuality is defined as discordance between sex assigned at birth and the gender identity constructed by a person throughout his/her life. Female transsexuality refers to individuals whose legal sexual identity is assigned by virtue of their masculine genitalia but who profoundly and consistently feel they belong to the female gender (male-to-female). The opposite occurs with male transsexuality (female-to-male). As a result, transsexual individuals frequently describe feeling trapped in a body that does not belong to them and suffer intense anguish as a result of discrimination experienced from very early ages.[1] To alleviate their anguish, many request psychological counseling and seek to alter their bodies through hormonal therapy and multiple surgical procedures to "adapt their bodies to their minds."[2]

The following example illustrates the conflict many transsexual individuals describe:[3]

Ana is a female transsexual who was assigned male sex at birth, determined by well-differentiated genitalia. From a very young age she felt that she was a girl; she gestured, played and dressed like a girl. Her family considered her a homosexual boy and violently rejected her: her father abused her physically and psychologically in an unsuccessful attempt to make her change. Ana's suffering worsened at puberty when, while beginning to develop masculine sexual traits, she persisted in dressing and acting like a young woman. The resulting rejection by her teachers and other students led her to leave school in ninth grade. Her first sexual experience occurred at age 15; she detested showing her genitalia during intercourse because "they weren't part of my body." Since adolescence, she received psychological treatment for dysphoric symptoms resulting from this suffering. When she was 26 years old, Ana mutilated her testicles, producing profuse bleeding and, accompanied by her partner, was rushed to the nearest women's hospital.

Transsexuality was considered an extreme form of homosexuality until 1973, when the American Psychological Association (APA) declassified homosexuality as a mental disorder. However, in 1980, the APA included transsexuality in the 3rd edition of the Diagnostic and Statistical Manual of Mental Disorders (DSM-III).[4] Today, transsexuality continues to be classified internationally as a mental disorder: it is included as a gender identity disorder in WHO's International Statistical Classification of Diseases and Related Health Problems (ICD-10) and in the APA's DSM-IV-R.[5,6]

The World Professional Association for Transgender Health (WPATH), founded in 1979, follows the ICD-10's diagnostic criteria for transsexuality:[7]

- The desire to live as and be accepted as a member of the opposite sex, usually accompanied by the desire to make one's body as congruent as possible with the desired sex through surgery and/or hormone treatment;

- Transsexual identity present for at least two years; and

- No symptom of another mental illness or chromosomal anomaly.

On this basis, WPATH established standards of care (SOC), practice guidelines based on consensus among experts and specialists for health care of transsexual persons, which can be adapted to specific conditions of health institutions and systems. These SOC are based on combining three therapeutic elements: reallife experience, hormonal treatment and sexual reassignment surgery (SRS). They stipulate that all transsexual persons should initially receive a mental health assessment by a team of specialists in psychology, psychiatry and psychometry, to determine if the gender identity "disorder" is a symptom of psychiatric illness. The team is also required to provide psychological accompaniment throughout the process of transition to the other sex.

These SOC require one and a half to two years of real-life experience living in the desired gender role, plus consolidation of changes desired from hormonal treatment, to determine if the person meets the criteria for transsexuality and is eligible for SRS. Real-life experience is meant to support optimal social integration through recognition and respect for the gender identity with which he or she identifies. Hormonal treatment involves administration of other-sex hormones (and of testosterone antagonists to male-to-female transsexuals as an adjuvant to feminizing treatment), to modify the transsexual's body towards the gender with which he or she identifies.

Lack of randomized clinical trials and in-depth followup studies involving transsexual persons who have received SRS makes it difficult to evaluate the surgery's benefits. However, SRS is considered to improve transsexuals' quality of life.[8] WPATH SOC state categorically that "SRS is not an experimental, investigative, elective, cosmetic or optional procedure; it is an appropriate and effective treatment for transsexuality or severe gender identity disorders." SOC also explicitly state that SRS should not be a requirement for legal identity change.[7]

WPATH protocols for hormone treatment and SRS involve eligibility and readiness criteria.[7]

- Eligibility: criteria that make an individual eligible to receive treatments related to gender reassignment (meet WPATH SOC definition of transsexuality and have no mental or physical contraindications).

- Readiness: consolidation of gender identity or improved mental health in the new or confirmed gender role. 
Although these criteria are considered useful to avoid diagnostic errors in treatments producing irreversible bodily changes, their normative, rigid and "one-size fits all" application forces transsexual persons to fit into them, in frank negation of the diversity of transsexual expression.

Our aim here is to discuss health care for transsexual persons in Cuba from a nonpathologizing and human rights perspective.

\section{TOWARDS DEPATHOLOGIZATION OF TRANSSEXUALTY IN CUBA}

Since 1979, transsexual persons in Cuba have been treated by multidisciplinary teams. Over the years, Cuba's diagnostic and treatment standards progressively have become aligned with WPATH SOC. In 2004, the National Commission for Comprehensive Attention to Transsexual People (CONAIT, the Spanish acronym) was established by the National Center for Sex Education (CENESEX, the Spanish acronym), a governmental organization within the Ministry of Public Health.

In 2005, CONAIT began designing the National Strategy for Comprehensive Attention to Transsexual People. The Strategy maintained and expanded the multidisciplinary approach beyond the biomedical to include legal and educational issues, as well as attention and support to transsexual persons' families and human resource capacity-building for national policymakers. $[9,10]$ Commission specialists provide centralized, universal and free services following treatment protocols based on international SOC and Ministry of Public Health Resolution 126 (2008), which mandated such comprehensive services.[11]

Despite this approach, and its intent to provide comprehensive care for transsexual persons in Cuba, difficult problems remain:

First, self-medication with other-sex hormones is practiced with alarming frequency, often before having any real-life experience. In our clinical practice, we see transsexual persons who selfmedicate to avoid developing secondary sexual characteristics or to transform their body autonomously and make it congruent with their gender identity. This reaffirms the need to ensure access to health services and accompaniment of transsexual persons in the transition process. This, in turn, raises the need to better publicize services available in Cuba, including their confidentiality.

Second, medical and psychological practice in Cuba is still based on international diagnostic criteria that classify transsexuality as a mental disorder. SRS is still a requirement for legal identity change, whether or not the individual wants surgery. Even if SRS is medically contraindicated, transsexual individuals cannot change their legally recognized sexual identity without surgery.

Third, Cuba's current legislation does not recognize this problem but reflects a binary gender model in which only masculinity-still dominant and hegemonic in our culture-and femininity (subordinate) are legitimized and defined according to genital biological characteristics. We consider this discriminatory, since it precludes other gender identities.

\section{CUBA IN THE GLOBAL DEBATE}

A heated international debate is under way on removal of transsexuality from the category of "disorders" in psychiatric diagnos- tic manuals, recognizing it instead as a legitimate expression of sexuality.[12]

Some professionals still take the position that transsexuality is a mental disorder, but this is unsupported by scientific evidence. $[13,14]$ The defining characteristic of a mental disorder is that "the behavior pattern of the person necessarily confers an adaptive disadvantage or causes him or her mental suffering."[7] However, application of this concept to transsexuality ignores the sociocultural causes of suffering and inequity resulting from patriarchal ideology, which lead to the behavior pattern that psychiatrists define as gender dysphoria.

The global debate is carried on in scientific, academic, political and legal circles, and involves advocacy groups defending the human rights of trans persons. Among the most important of these groups is the International Network for Trans Depathologization, comprised of activists worldwide, civil society organizations, scientific societies and political figures who raise the profile of this issue. The Network's demands include the right to change name and gender in official documents without medical or psychological evaluation, as well as to freely decide to modify one's body without bureaucratic, political or economic obstacles and without medical coercion.[15] These demands are polemical, as they not only aim at legitimizing recognition and respect for trans identities, but question current legislation and medical practice in many countries.

Contradictions persist among positions of the various Cuban government bodies and civil society, including professional organizations. In January 2010, at the request of CONAIT (a CENESEX-established commission), the Cuban Multidisciplinary Society for Sexuality Studies (SOCUMES, the Spanish acronym) issued a Declaration on Depathologizing Transsexuality, which argued that: "(diagnostic) classifications of transsexuality perpetuate and deepen social discrimination against these persons, causing irreversible physical and psychological damage that can lead to suicide."[16]

The declaration also calls for "application of all medical and surgical procedures that respect each person's sexual rights and are consistent with bioethical principles of autonomy, nonmaleficence and justice." CONAIT and SOCUMES support the International Campaign for Trans Depathologization.[16] And even though they do not consider transsexuality to be a mental disorder, both these Cuban organizations consider it indispensable to guarantee access to comprehensive health care for trans persons. In this context, CONAIT adheres to international SOC only as a guide for treatment, without sharing their underlying assumption of transsexuality as a disorder. In addition, individuals treated by CONAIT have absolute freedom to decide about their bodies, and all medical interventions require informed consent. A transsexual person can abandon followup at any phase in the protocol.

On the legal front, CONAIT, in collaboration with the National Union of Cuban Jurists, has submitted a draft Gender Identity Law that would, if approved by parliament, guarantee gender identity recognition for a transsexual individual without requiring SRS.

We have more work to do to reach consensus with the Cuban Psychiatric Society, which still considers transsexuality a gender 
identity disorder. We also need to adapt our medical protocols to the terms of the Declaration.

In the global arena, removal of transsexuality from the list of mental disorders is controversial and could result in denial of health insurance or coverage in many countries, particularly those where care for transsexuals has become a lucrative business.[17] During the 21st WPATH Symposium in 2009, many experts agreed that transsexuality does not in and of itself constitute a mental illness, and that transitional treatments (hormones and surgery) to alleviate gender dysphoria are medically necessary and should be covered by health insurance.[18] In Cuba, the universal, free and public health system provides a secure foundation for treatment in keeping with the social and psychological vulnerability of transsexual persons and respect for the human right to health.

\section{HEALTH CARE FOR TRANSSEXUAL PERSONS AS A HUMAN RIGHT}

The UN High Commissioner for Human Rights defines health as a basic human right and essential to what we understand to be a dignified life: the right to enjoy the highest possible level of physical and mental wellbeing.[19]

Thus, denial of health care for transsexual persons is a violation of human rights. Far from being mentally ill, transsexual persons require comprehensive attention to help mitigate the negative mental health impact of discrimination, which is why efforts in Cuba are made in this direction, irrespective of cost to institutional providers.

The Yogyakarta Principles, based on international human rights laws on sexual orientation and gender identity, provide another guide to activists and policymakers.[20] While not legally binding, these principles constitute an advocacy tool on sexual diversity issues, both for activists and states. Although they are interdependent, two principles are most important in relation to transsexuality:

- Principle 2 refers to equality and nondiscrimination and states that discrimination on the basis of sexual orientation or gender identity includes "any distinction, exclusion, restriction or preference based on sexual orientation or gender identity which has the purpose or effect of nullifying or impairing equality before the law."[20] In Cuba and many other countries, these fundamental principles of human rights are not made explicit in legislation, since trans identities are not recognized as legitimate. Thus, civil and economic rights of transsexual persons are thwarted and, stigmatized for not adapting to binary gender norms, these people are denied social insertion and participation in political life.[21] Cuba needs an educational strategy for decisionmakers and the entire population and to advocate for explicit recognition of trans persons' human rights and full inclusion of these rights in policies. These initiatives are needed to bring about a cultural shift on gender identity and to achieve full respect for and recognition of sexual rights.

- Principle 18 states that regardless of any contrary diagnostic classification, an individual's sexual orientation and gender identity in and of themselves do not constitute health disorders and should not be suppressed or subjected to medical treatment.[20] This principle is controversial in Cuba, since our medical procedures adjust transsexuals' bodies to socially-accepted binary gender categories. We need medical protocols that improve these individuals' comprehensive health, free of inappropriate medical practices and irreversible iatrogenic effects.

CONAIT's position is not to treat transsexuality as a mental disorder, but to address the ills produced by discrimination against transsexual persons. Hence, all health actions we take are aimed at relieving these persons' suffering, with full respect for their personal dignity, as a human rights principle.

\section{PENDING A CULTURAL SHIFT}

In Cuba, comprehensive and free care is ensured, aimed at relieving the ills and suffering of transsexual persons. Nevertheless, until we have a cultural shift through education of the entire society on transsexuality and nonhegemonic gender relationslegitimizing diversity of human sexuality-and gradual adoption of a new equity-based gender paradigm free of power relations and exclusion, it should be the state's obligation to guarantee health legislation and policies that protect the rights of transsexual persons, free of pathologizing and discriminatory approaches.

\section{ACKNOWLEDGMENTS}

This manuscript would not have been possible without input from CONAIT colleagues and, above all, contributions from transsexual persons who have confided in us. -1 -

\section{REFERENCES}

1. Becerra A. Transexualidad. La búsqueda de una identidad. Madrid: Ed. Díaz Santos; 2003. Spanish.

2. Expediente correspondiente a Y.C.R. Archivos de la Comisión Nacional de Atención Integral a Personas Transexuales. Havana: CENESEX; 2007. Spanish.

3. Gooren LJ. Care of Transsexual Persons. Massachusetts: Massachusetts Medical Society; 2011. p. 1251-7.

4. Zucker KJ, Spitzer RL. Was the gender identity disorder of childhood Diagnosis introduced into DSM-III as a backdoor maneuver to replace homosexuality? A historical note. J Sex Marital Ther. 2005 Jan-Feb;31(1):31-42.

5. American Psychiatric Association. Diagnostic and Statistical Manual of Mental Disorders. 4th ed. Washington: American Psychiatry Pub; 2000 Jun. 943 p.
6. World Health Organization. Programmes and Projects [Internet]. Geneva: World Health Organization; c2012. International Classification of Diseases; 2010 [cited 2011 Sep 6]. Available from: www.who.int/classifications/icd/en/

7. Standards of Care for Gender Identity Disorders. Sixth Version [Internet]. Minneapolis (US): World Association for Transgender Health; 2001. 22 p. Available from: http://www.wpath.org /documents2/socv6.pdf

8. Monstrey S, Vercruysse H Jr, De Cuypere G. Is Gender Reassignment Surgery Evidence Based? Recommendation for the Seventh Version of the WPATH Standards of Care. Int J Transgenderism. 2009;11(3):206-14.

9. Castro M. La atención a transexuales en Cuba y su inclusión en las políticas sociales. In: Mariela C, Alfonso A, Prieto M, Roque A, Padrón R,
Rodríguez M, editors. La Transexualidad en Cuba. Havana: CENESEX; 2008. p. 31-40. Spanish.

10. Alfonso A, Rodríguez M. Familias y personas transexuales. Una relación al desnudo. Sexología y Sociedad. 2009;15(40):32-9. Spanish.

11. Resolución Ministerial No. 126. Havana: Ministry of Public Health (CU); 2008. Spanish.

12. Fraser L, Karasic DH, Meyer WJ 3rd, Wylie K. Recommendations for Revision of the DSM Diagnosis of Gender Identity Disorder in Adults. IJT. 2010 Apr;12(2):80-5.

13. Blanchard R. Early history of the concept of autogynephilia. Arch Sex Behav. 2005 Aug;34(4):439-46.

14. Zucker KJ, Bradley SJ, Owen-Anderson A, Singh $D$, Blanchard R, Bain J. Puberty-blocking hormonal therapy for adolescents with gender iden- 
tity disorder: A descriptive clinical study. J Gay Lesbian Mental Health. 2011;15:58-82.

15. STOP PATOLOGIZACION TRANS. Red Internacional por la Despatologización de las Identidades Trans [Internet] [cited 2011 Sep 7]. Available from: http://stp2012.wordpress.com. Spanish.

16. ILGA [Internet]. Declaración sobre Despatologización de la Transexualidad adoptada en Asamblea General de la Sociedad Cubana Multidisciplinaria para el Estudio de la Sexualidad [Internet]. Bruxelles: International Lesbian, Gay, Bisexual, Trans and Intersex Association; 2010 Jan 22 [cited 2011 Sep 7]; [about 1 screen]. Available from: http://ilga.org/ilga/es/article/ mg6JSED110. Spanish.

17. El Derecho a la Salud. Folleto informativo No. 31. Geneva: World Health Organization; 2008. Spanish.

18. Clarification on medical necessity of treatment, sex reassignment, and insurance coverage in the USA [Internet]. Minneapolis (US): World Professional Association for Transgender Health; 2008 Jun 17 [cited 2011 Sep 7]. 4 p. Available from: http://www.wpath.org/documents/Med\%20 Nec\%20on\%202008\%20Letterhead.pdf.

19. Special Rapporteur on the right of everyone to the enjoyment of the highest attainable standard of physical and mental health. Office of the UN High Commissioner for Human Rights. [cited 2010Apr 5]. Available from: http://www .ohchr.org/EN/Issues/Health/Pages/SR RightHealthlndex.aspx

20. The Yogyakarta Principles [Internet]. [place unknown]: [author unknown] Principles on the application of international human rights law in relation to sexual orientation and gender identity. 2007 Mar [cited 2011 Sep 2]. Available from: http//www.yogyakartaprinciples.org.

21. Hammarberg T. Derechos humanos e identidad de género. Informe temático [Internet]. Berlin:
Publicaciones TvT; 2010 [cited 2011 Sep 9]. Available from: www.transinqueer.org. Spanish.

\section{THE AUTHORS}

Alberto Roque Guerra (Corresponding author: aroqueg@infomed.sld.cu), internist, National Sex Education Center (CENESEX), Havana, Cuba.

Rosa Mayra Rodríguez Lauzurique, psychologist, CENESEX, Havana, Cuba.

Submitted: September 10, 2011

Approved for publication: April 6, 2012

Disclosures: None 